\title{
Os nomes e usos de palmeiras entre uma tribo de índios Yanomama
}

\author{
Anthony B. Anderson (")
}

\begin{abstract}
Resumo
Referências sobre 20 principais espécies de palmeiras utilizadas pelos Xiriana-teri, uma tribo de índios Yanomama, localizada ao norte do Estado do Amazonas, Brasil. Os nomes comuns (indígenas e brasileiros) e científicos de cada espécie são mencionados. Os usos que os Xiriana-teri fazem das palmeiras são examinados detalhadamente, concluindo-se que eles as utilizam em grau muito menor do que outras tribos de diversas regiōes tropicais da América do Sul. Em grande parte, isso é devido aos aspectos materiais de sua cultura, bastante rudimentares em relação a outras tribos. Também, segundo observações do autor, houve no passado uma superexploração de espécies economicamente importantes nas proximidades da aldeia, o que é um fator importante na limitação atual dos usos que os Xiriana-teri fazem das palmeiras.
\end{abstract}

\section{INTRODUÇão}

Os índios Yanomama formam um grupo tribal pouco definido, localizado na fronteira entre a Venezuela e o Brasil. Suas 150 ou mais aldeias estão espalhadas numa área de aproximadamente $150.000 \mathrm{~km}^{2}$, definida pelo Equador e latitude $5^{\circ}$ Norte e pelas longitudes $61^{\circ}$ e $66^{\circ} 30^{\prime}$ Oeste (Spielman et al., 1974). Os Yanomama representam um dos grupos tribais relativamente grandes e menos aculturados que ainda permanecem na América do Sul. Somente nos últimos 20 anos foram estabelecidos contatos permanentes com o mundo exterior.

O presente trabalho se refere a uma das tribos dos Yanomama, denominada "Xiriana-teri" ${ }^{n}$, localizada no Estado do Amazonas, Brasil, adjacente à fronteira com a Venezuela (latitude $1^{\circ} 44^{\prime}$ Norte, longitude $63^{\circ} 39^{\prime}$ Oeste). Sua aldeia fica na margem oeste do rio Toototo$b^{(1)}$, um afluente do rio Demeni, que é, por sua vez, um dos principais afluentes do rio
Negro. A região que lhes serve de habitat tem uma altitude de aproximadamente $180 \mathrm{~m}$ acima do nível do mar, e é continuamente coberta por floresta tropical alta: o reconhecimento aéreo da vizinhança da aldeia não revelou sinais de savanas, as quais ocorrem cerca de 250 quilômetros a leste, no Território Federal de Roraima. Os Xiriana-teri ocupam a mesma localidade em Toototobi há pelo menos 15 anos, desde a chegada de um missionário protestante e sua família.

Embora os contatos com o mundo exterior tenham influenciado a vida material e espiritual dos índios, a sua cultura tradicional parece ter permanecido praticamente intacta. Além da pintura do corpo, nenhuma outra arte pictórica é praticada. Não fazem trabalhos em cerâmica e a tecelagem é relativamente rara. $\mathrm{O}$ aspecto material de sua cultura limita-se a um nível simples de sobrevivência, observação válida para todas as tribos de Yanomama (Chagnon, 1968).

\section{MÉtodos E RESULTADOS}

Poucos trabalhos etnobotânicos sobre os Yanomama aparecem na literatura; só conhecemos os de Schultes \& Homstedt (1968) e o de Cocco (1972). Embora haja uma série de referências valiosas sobre o uso de palmeiras entre os indios amazônicos (cf. Wallace, 1853; Levi-Strauss, 1950, Civrieux, 1957; Wilbert, 1976), há somente ligeiros comentários sobre o uso de palmeiras entre os Yanomama (Chagon, 1968; Cocco, 1972; Smole, 1976). A atual falta de informações sobre o papel das palmeiras na vida dos Yanomama é resultante do relativo isolamento desse grupo indígena e das enormes dificuldades que existem na coleta de espécies de palmeiras a serem identifica-

$(\cdot)$ - Instituto Nacional de Pesquisas da Amazônia, Manaus.

(1) - O rio e a aldeia foram chamados "Tototobi" na literatura (Schultes \& Holmstedt, 1968). Porém, "Toototobi" é o nome encontrado na literatura mais recente (e.g. Spielman et al., 1974), e é também o nome do rio, segundo a edição de 1972 da Carta do Brasil ao Milionésimo. (I.B.G.E., Rio de Janeiro). 
das. O estado confuso da taxonomia de uma série de gêneros grandes de palmeiras que são tipicamente amazônicas - tais como Astrocaryum, Bactris e Euterpe -, não colabora muito para melhorar a situação presente.

A falta de conhecimento em relação à etnobotânica e taxonomia das palmeiras amazônicas inspirou-me a dedicar-me ao seu estudo durante uma curta visita a Toototobi, em agosto de 1975. Fiz intensivas coletas de amostras nas proximidades da aldeia; devido às limitaçōes de tempo, só coletei as espécies de palmeiras que desconhecia. As amostras originais estão depositadas no herbário do Instituto Nacional de Pesquisas da Amazônia (INPA); as duplicatas obtidas foram enviadas ao Bailey Hortorium em Ithaca, New York, EUA.

Um dos maiores problemas que enfrentei, enquanto coletava palmeiras em Toototobi, surgiu do fato de que os índios não têm uma palavra e, aparentemente, nenhum conceito equivalente à nossa noção da palavra "palmeira". Os Xiriana-teri dividem as plantas em dois grupos principais: um deles representa as árvores dicotiledôneas e é denominado pelo sufixo -hiki; o outro, denominado pelo sufixo -siki, representa as criptógamas e também as fanerógamas. Nestas estão incluídas árvores, cipós e ervas que são predominantemente monocotiledôneas (e.g. Palmae, Gramineae, Marantaceae, Araceae, etc.), e também algumas ervas e trepadeiras que são dicotiledôneas (como o algodão). É certo que os Xiriana-teri empregam um esquema de classificação de plantas sofisticado e complexo, como Taylor mostra em seu trabalho (1974) sobre classificação de animais entre uma tribo vizinha dos Yanomama.

De qualquer maneira, as limitações de tempo impossibilitaram-me de compreender melhor as complexidades da taxanomia dos Xiriana-teri. Com a falta de uma palavra que expressasse a noção de "palmeira", fui obrigado a pedir aos índios informantes que me mostrassem todas as plantas denominadas "-siki". O Dr. Ghillean Prance, do New York Botanical Garden, com quem viajei, adaptou um esquema mais eficiente para acumular uma formidável coleção de cogumelos: simplesmen- te pediu aos indios que conseguissem as amostras para ele. Infelizmente, as palmeiras não são tão fáceis de coletar: atendendo ao meu pedido que coletassem uma série das plantas pertencentes à categoria $-s i k i$, os índios prudentemente ignoraram as palmeiras e trouxeram-me uma excelente coleção de cipós e bambus.

Além de coletar as palmeiras, consegui o máximo possível de informações sobre seus nomes e usos entre os Xiriana-teri. Embora nem todas as palmeiras que ocorrem na vizinhança de Toototobi estejam incluídas neste artigo, as espécies economicamente mais importantes certamente o estão.

Os resultados estão resumidos na Tabela 1.

\section{DISCUSSÃO}

COMIDA E BEBIDA

Chagnon (1968) relata que os frutos das palmeiras constituem o alimento vegetal mais importante de todos os conseguidos na mata pelos Yanomama. Isto parece ser também verdade entre os Xiriana-teri, que dependem de um grande número de espécies de palmeiras para obterem frutos comestiveis. (Os índios se referem aos frutos, sementes e plântulas como "moki"). Provavelmente, a espécie mais importante é a Bactris gasipaes (=Guilielma gasipaes Bailey), cultivada em todas partes dos trópicos americanos. Esta espécie pode não ser nativa da Amazônia e ainda não foi encontrada na mata; pode ter sua origem nos Andes colombianos, onde ocorre uma espécie similar (observações no campo de H.E. Moore Jr. e A.B. Anderson, 1974, não publicadas). Os frutos da $B$. gasipaes são cozidos e têm excelente sabor. A colheita ocorre em fevereiro ou março, e, infelizmente, não havia um só pé com frutos durante a época da minha visita (agosto).

Outro fruto comum entre os Xiriana-teri é o da Orbignya spectabilis; durante a minha visita, cada família tinha um suprimento desses frutos, que eram comidos crus a qualquer hora do dia. 
T A B E L A

OS NOMES E USOS DAS PALMEIRAS ENTRE OS XIRIANA-TERI.

\begin{tabular}{|c|c|c|c|c|c|c|c|c|c|}
\hline \multirow[b]{2}{*}{$\begin{array}{l}\text { NOME } \\
\text { INDIGENO }\end{array}$} & \multirow[b]{2}{*}{$\begin{array}{l}\text { NOME } \\
\text { BRASILEIRO }\end{array}$} & \multirow[b]{2}{*}{ NOME CIENTIFICO } & \multicolumn{7}{|c|}{ usos } \\
\hline & & & Frutos & Palmitos & $\begin{array}{l}\text { Cobertu- } \\
\text { tura de } \\
\text { Tetos }\end{array}$ & $\mid \begin{array}{c}\text { Madeira } \\
\text { para } \\
\text { Construção }\end{array}$ & Arcos & $\begin{array}{l}\text { Ponta- } \\
\text {-de- } \\
\text {-Flecha }\end{array}$ & $\begin{array}{l}\text { Outros } \\
\text { Usos }\end{array}$ \\
\hline Dorea . & $\begin{array}{l}\text { Caraná ou } \\
\text { Caranaí }\end{array}$ & $\begin{array}{l}\text { Mauritia aculeata } \\
\text { H.B.K. }\end{array}$ & $x$ & & & & & & \\
\hline Liōkoho - & Buriti & Mauritia flexuosa L. & $\mathrm{X}$ & & & & & & \\
\hline Manaka - & Paxiuba & $\begin{array}{l}\text { Socratea exorrhiza } \\
\text { (Mart.) H. Wendl. }\end{array}$ & & & & $\mathrm{x}$ & $\mathrm{x}$ & $\mathrm{X}$ & \\
\hline Bahanaki - & Ubím & $\begin{array}{l}\text { Geonoma baculifera } \\
\text { (Poit.) Kunth }\end{array}$ & & & $\mathrm{x}$ & & & & $\mathrm{x}$ \\
\hline Wanama - & Ubím & $\begin{array}{l}\text { Geonoma deversa } \\
\text { (Poit.) Kunth }\end{array}$ & & & $\mathrm{x}$ & & & $\mathrm{X}$ & $\mathrm{X}$ \\
\hline Kunuana : & $\begin{array}{l}\text { Palha ver- } \\
\text { melha }\end{array}$ & $\begin{array}{l}\text { Orbignya spectabilis } \\
\text { (Mart.) Burret }\end{array}$ & $\mathrm{x}$ & & & $\mathrm{x}$ & & $\mathrm{x}$ & \\
\hline Okolaxi - & Inajá & $\begin{array}{l}\text { Maximiliana regia Mart. } \\
(=\mathbf{M} \text {. martiana } \mathrm{H} . \\
\text { Karst. })\end{array}$ & $\mathrm{x}$ & $\mathrm{x}$ & & & & & \\
\hline Yoi - & Urucuri & $\begin{array}{l}\text { Scheelea martiana } \\
\text { Burret }\end{array}$ & $\mathrm{x}$ & $\mathrm{x}$ & & 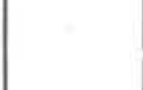 & & & \\
\hline Ai-amo - & & $\begin{array}{l}\text { Astrocaryum aff. acu- } \\
\text { leatum G.F.W. Meyer. }\end{array}$ & $\mathrm{x}$ & $\mathrm{x}$ & & & & $\mathrm{x}$ & $\mathrm{x}$ \\
\hline Mahã - & Murumuru & $\begin{array}{l}\text { Astrocaryum murumu- } \\
\text { ru Mart. }\end{array}$ & $\mathrm{x}$ & $\mathrm{x}$ & & & & & \\
\hline Uri - & Tucumã & $\begin{array}{l}\text { Astrocaryum vulgare } \\
\text { Mart. }\end{array}$ & $\mathrm{X}$ & $\mathrm{x}$ & & & & & \\
\hline Xohomo - & & Astrocaryum sp. & $\mathrm{x}$ & $\mathrm{x}$ & & & & & \\
\hline Lasa . & Pupunha & Bactris gasipaes H.B.K & $\mathrm{x}$ & $\mathrm{x}$ & & & $\mathrm{x}$ & $\mathrm{x}$ & \\
\hline Mokamo - & Marajá & Bactris sp. & $\mathrm{x}$ & $\mathrm{x}$ & & & & $\mathrm{x}$ & \\
\hline Yarimo - & Marajá & Bactris sp. & $\mathrm{x}$ & $\mathrm{x}$ & & $\mathrm{x}$ & & $\mathrm{X}$ & \\
\hline Yoroa - & Marajá & Bactris sp. & $\mathrm{x}$ & $\mathrm{x}$ & & $\mathrm{x}$ & & $\mathrm{x}$ & \\
\hline Yoyoma . & Marajá & Bactris sp. & $\mathrm{X}$ & $\mathrm{X}$ & & & & & \\
\hline Hokoma - & Bacaba & $\begin{array}{l}\text { Oenocarpus bacaba } \\
\text { Mart. }\end{array}$ & $\mathrm{x}$ & $\mathrm{x}$ & & & $\mathrm{x}$ & $\mathrm{x}$ & $\mathrm{x}$ \\
\hline Koanani . & Patauá & $\begin{array}{l}\text { Jessenia bataua } \\
\text { (Mart.) Burret }\end{array}$ & $\mathrm{x}$ & $\mathrm{x}$ & & & $\mathrm{x}$ & $\mathrm{x}$ & $\mathrm{x}$ \\
\hline$\underset{s}{\text { Maima }}$ & Açaí & $\begin{array}{l}\text { Euterpe precatoria } \\
\text { Mart. }\end{array}$ & $\mathrm{x}$ & $\mathrm{x}$ & & $\mathrm{x}$ & & & $\mathrm{x}$ \\
\hline
\end{tabular}

Os nomes e usos... 
Mauritia flexuosa e M. aculeata também provêem frutos comestíveis, que são bastante procurados pelos índios. Eles deixam esses frutos imersos na água por alguns dias, após o que a cobertura externa é facilmente retirada, expondo uma fina camada de polpa que tem o sabor de queijo. Os Xiriana-teri também preparam sucos dos frutos dessas espécies. Entretanto, $M$. flexuosa e $M$. aculeata estão se esgotando na vizinhança de Toototobi, aparen- temente devido à grande exploração feita pelos índios. Os frutos da $M$. flexuosa são altamente nutritivos, assim como os da Astrocaryum vulgare, que são também muito populares entre os Xiriana-teri: ambos contêm três vezes mais vitamina $A$ do que as cenouras (Pechnik et al., 1947).

Provavelmente, durante todos os meses há uma ou outra das muitas espécies de palmeiras que produzem frutos comestíveis. Mes-

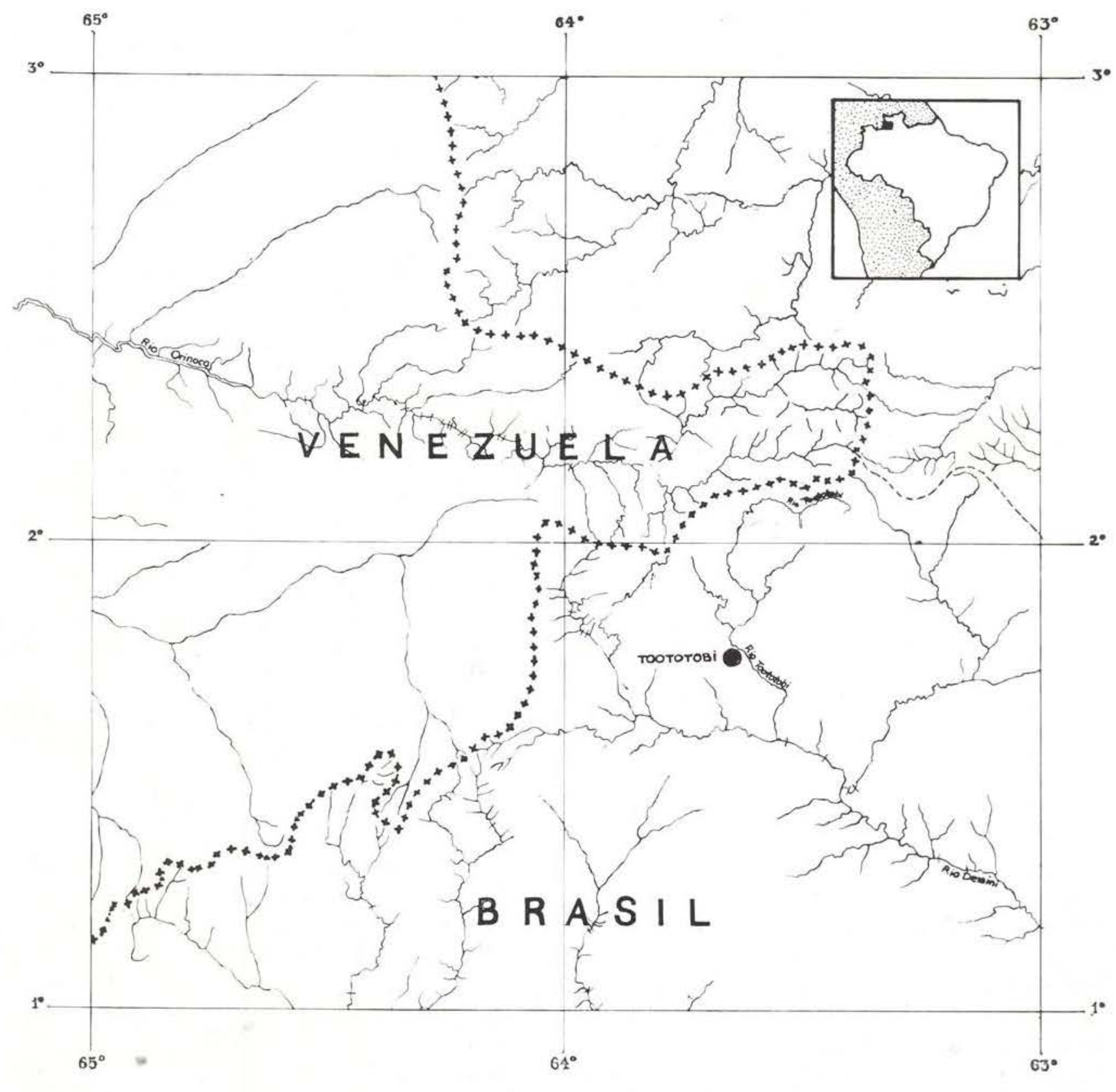

Fig. 1 - Mapa mostrando a localização de Toototobi. 
mo assim os Xiriana-teri são, aparentemente, menos imaginativos do que outras tribos amazônicas quanto ao repertório de comidas e bebidas derivadas de frutos de palmeiras. Wallace (1853) relatou que, na região do rio Negro, os índios extraem um óleo transparente e inodoro dos frutos da Oenocarpus bacaba, que é usado para cozinhar e também, ocasionalmente, para acender lamparinas. O uso de óleo de palmeiras parece ser um fenômeno comum entre as tribos amazônicas, de acordo com Levi-Strauss (1950). Ele também descobriu que, além dos usos medicinais, o óleo é freqüentemente misturadio com pigmentos para fazerem pinturas no corpo. Mas, aparentemente, é pouco usado entre os Xiriana-teri. Eles extraem um óleo fervendo os frutos de Mauritia flexuosa, o qual é então misturado com água e esfregado sobre pães de mandioca.

$\mathrm{Na}$ região do rio Negro, Wallace (1853) descobriu que os frutos de Bactris gasipaes são transformados num tipo de farinha, que é então torrada para fazer bolos ou deixada em fermentação na água; este último processo é o de produção de um vinho cremoso. Segundo Levi-Strauss (1950), os índios amazônicos obtêm bebidas ou mingaus das seguintes espécies: Euterpe precatoria, Oenocarpus bacaba, Jessenia bataua, Mauritia flexuosa e Maximiliana regia. Embora estas espécies ocorram na vizinhança de Toototobi, tais bebidas ou mingaus são praticamente desconhecidos entre os Xeriana-teri.

Por toda a América tropical, espécies do gênero Euterpe fornecem um alimento muito procurado: o palmito. Entre os Xiriana-teri, os palmitos (denominados "amoki") da espécie Euterpe precatoria são considerados superiores. Outras espécies de gêneros relacionados (subfamília Arecoidae) são do mesmo modo favorecidas quanto a seus palmitos: Jessenia bataua e Oenocarpus bacaba. A Bactris gasipaes cultivada também é pcpular. Na verdade os Xiriana-teri comem os palmitos da maioria das espécies locais. Embora a extração do palmito mate a palmeira, isto parece não deter os índios em sua ávida procura de alimentos. Além do mais, o missionário de Toototobi me informou que, com exceção da $B$. gasipaes cultivada, os índios normalmente obtêm fru- tos comestíveis e palmitos, simplesmente derrubando as palmeiras.

Entre outras tribos de Yanomama, as palmeiras servem como fonte adicional de alimento. Chagnon (1968:30-31), descreve o uso que os Yanomama fazem de troncos caídos de palmeiras, como lugares de coleta de larvas comestiveis:

Os Yanomamö se aproximam muito do que se chama "domesticação de animais", em suas técnica de exploração deste alimento. Derrubam as palmeiras deliberadamente a fim de obter forragem para os insetos. Quando cortam a paimeira, também comem o palmito, que é um alimento vegetal muito saboroso... Uma palmeira que cortamos tinha um palmito comestivel de aproximadamente $20 \mathrm{~kg}$. Depois de deixar o estipe apodrecer por vários meses, ele acumula uma enorme quantidade de larvas brancas e grandes. A madeira é retirada da palmeira com varetas, aberta com as măos e as larvas então são extraídas. Cada larva é mordida atrás de sua cabeça retorcida, e a cabeça e os intestinos são removidos simplesmente puxando o corpo para fora com os dentes. Se a larva fica danificada durante o processo de extraçăo, as partes são comidas cruas ali mesmo. Uma palmeira razoavelmente grande sustentará até $2 \mathrm{~kg}$ de larvas, algumas delas tão grandes como um rato. As larvas são embrulhadas em pequenas embalagens de folhas e colocadas na brasa para assar... Nunca tive coragem de comer uma, mas um missionário experiente disse-me que elas têm o sabor muito parecido com bacon... As sementes dos frutos das palmeiras que são jogadas fora também ficam infetadas com larvas menores. Os Yanomamö quebram as sementes duras com uma pedra até abri. rem, extraem as larvas e preparam-nas da mesma maneira.

Chagnon baseou suas observações em tribos de Yanomama situadas ao norte, principalmente na Venezuela. Quando perguntamos aos índios de Toototobi se eles praticavam esta forma de "domesticação animal", continuamente recebemos respostas negativas. Segundo o missionário, a domesticação de qualquer animal, exceto ocasionalmente um animal de estimação, é basicamente contrária ao modo de pensar dos Xiriana-teri.

\section{CONSTRUÇÃo}

A palmeira que fornece a madeira de construção mais valorizada entre os Xiriana-teri é a Euterpe precatoria. A madeira desta espécie é durável e também macia e fácil de ser traba- 
Ihada: é usada principalmente para fazer ripas de paredes, tampos de mesa e prateleiras. A Socratea exhorriza é preferida para o feitio de ripas de teto, embora a Orbignyia spectabilis, e também duas espécies de Bactris (Yarino-siki e Yoroa-sikì), são ocasionalmente usadas para o mesmo fim. Comparados com outras tribos, entretanto, os Xiriana-teri não dependem tanto das palmeiras para a construção. Entre outros índios da Amazônia, por exemplo, a Socratea exhorriza é amplamente empregada para a construção de postes, cercas, paliçadas, assoalhos de canoas, prateleiras e assentos (Wallace, 1853; Levi-Strauss, 1950); talvez esta espécie não seja tão usada pelos Xiriana-teri devido a sua escassez na floresta próxima à aldeia.

A Geonoma baculifera, uma palmeira muito comum na vizinhança de Toototobi, é a principal origem das coberturas de teto. Os Xiriana-teri também utilizam as folhas de $G$. deversa para cobrir tetos, embora esta espécie seja consideravelmente menos preferida. As folhas da maioria das espécies de Geonoma não são muito duráveis, mas, segundo Braun (1968), são usadas pela maioria das tribos de indios na Venezuela porque existem em aburdância. Isto parece acontecer também entre as tribos do Brasil. Wallace (1853) referiu-se a uma espécie de Geonoma, provavelmente $G$. baculifera, que ocorre em abundância nas áreas inundadas próximas ao rio Negro; esta espécie era (e, provavelmente, ainda é) muito usada para cobertura de teto pelos índios desta região.

\section{USOS VARIADOS}

Os Xiriana-teri utilizam várias palmeiras para o fabrico de arcos e pontas-de-flechas. Quatro espécies são utilizadas para fazer arcos, na seguinte ordem decrescente de preferência: Socratea exhorriza, Bactris gasipaes, Oenocarpus bacaba e Jessenia bataua. As duas primeiras espécies, entretanto, não são freqüentemente usadas para fazer arcos. A $S$. exhorriza é relativamente rara na floresta próxima a Toototobi, e sua madeira é considera- da mais valiosa para fins de construção. A B. gasipaes, que Wallace (1853) considerou como sendo a madeira mais resistente de todas as palmeiras, é cultivada e considerada extremamente valiosa pelos seus frutos. Somente a $O$. bacaba e J. bataua ocorrem comumente na floresta vizinha, e talvez por isso os índios geralmente fazem seus arcos com a madeira dessas espécies. A fabricação de um arco é um processo meticuloso que requer cerca de dois dias de trabalho. Entre os Xiriana-teri, as facas de metal servem como ferramentas para cortar, provavelmente substituindo o maxilar inferior de queixada (Tayassu spp.), que é usado por outras tribos de Yanomama para moldar arcos (Chagnon, 1968). O produto final é forte, durável e muito difícil de estirar.

Os Xiriana-teri utilizam cerca de 10 espécies de palmeiras (Tabela 1) para a confecção de pontas-de-flecha. A Socratea exhorriza parece ser, novamente, a espécie mais adequada para este fim, embora certamente não seja a mais usadia. A ponta-de-flecha é feita de uma lasca de madeira da palmeira. Algumas vezes os indios talham fendas laterais ao longo da ponta-de-flecha, o que faz com que ela quebre dentro do corpo da caça. As pontas-de-flecha são impregnadas com um veneno derivado da resina de Virola theiodora (Myristicaceae) (2), e se tornam, assim, especialmente efetivas para caçar macacos, os quais tendem a se agarrar aos galhos quando feridos; o veneno atua como relaxador muscular e, eventualmente, os macacos caem ao chão.

Em relação a armas, fui informado de que a madeira de Jessenia bataua é usada de vez em quando pelos Xiriana-teri para a confecção de clavas; a densidade da madeira dessa palmeira deve fazer com que tais clavas sejam terrivelmente efetivas. Segundo Chagnon (1968), lutas com clavas são bastante comuns entre os Yanomama, geralmente por causa de discussões sobre mulheres.

Os Xiriana-teri freqüentemente usam foIhas de palmeiras para tecer cestas provisórias; Geonoma baculifera, G. deversa e Jessenia bataua são preferidas para esse fim. As folhas de Maximiliana regia e $J$. bataua são te-

(2) - A resina desta espécie é também o principal ingre diente utilizado na preparaçăo de um rapé alucinogênico. 


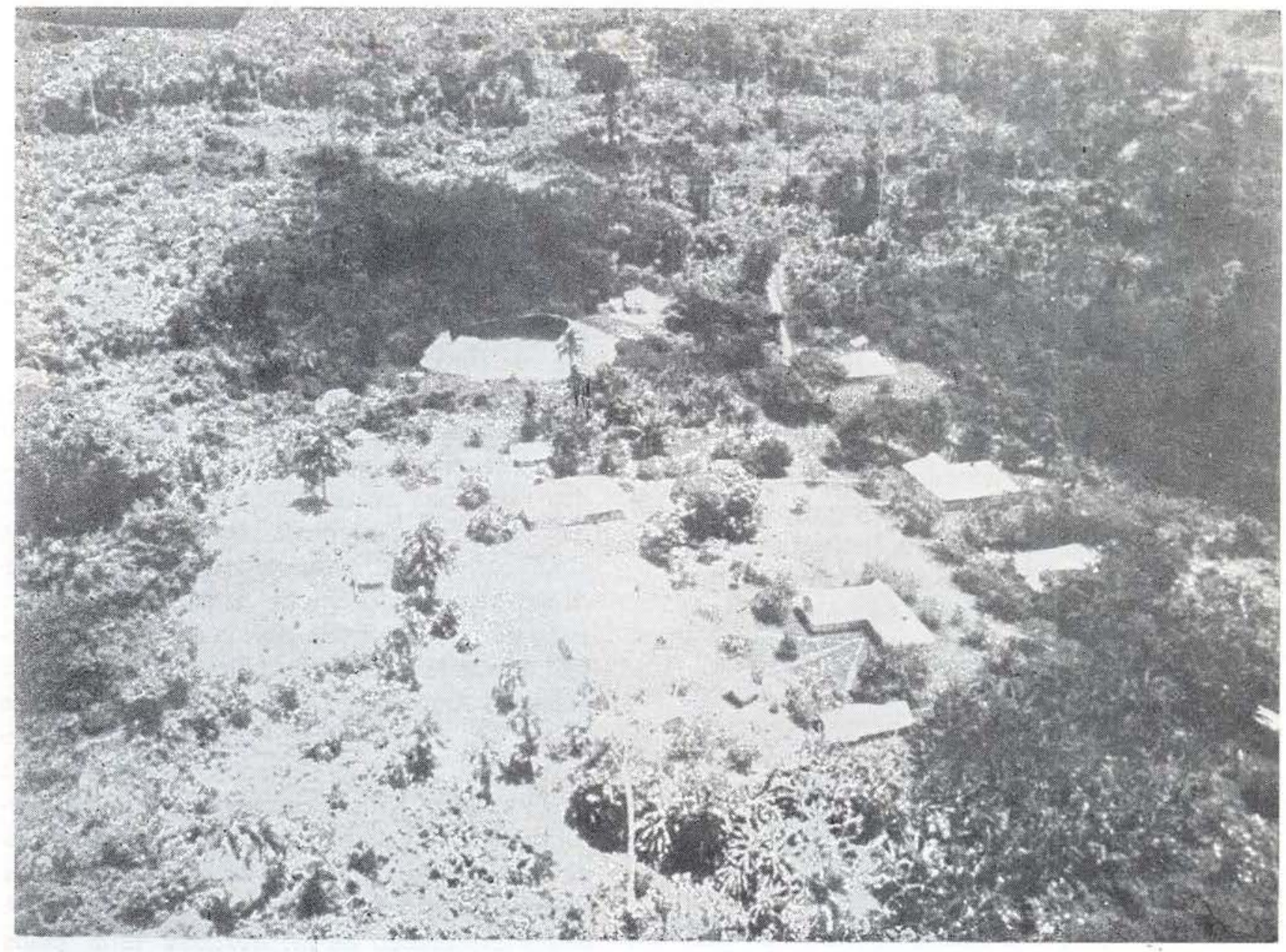

Fig. 2 - Vista aérea da vila de Xiriana-teri, em Toototobi. A grande estrutura circular ao fundo é a maloca, uma moradia comunal encontrada em muitas tribos da Amazônia.

cidas ao mesmo tempo e colocadas junto às paredes e portas de moradias, aparentemente com finalidades decorativas; telas tecidas com folhas dessas espécies servem também para demarcar a área de cada família dentro da maloca. Isto, juntamente com a cobertura de teto, mostra no que são empregadas as fibras e folhas de palmeiras entre os Xiriana-teri.

Em termos de decoração do corpo, o uso de palmeiras também é limitado. Os Xiriana-teri pintam seus corpos em ocasiões de cerimônias, mas só raramente usam corantes extraídos de palmeiras: os frutos de Jessenia bataua produzem um corante azul escuro, e os de "Euterpe precatoria, um corante preto. Eles sabem de tribos vizinhas que fazem anéis dos frutos do que parece ser Astrocaryum aff. acu- leatum, mas eles mesmos não os fazem, embora esta espécie seja comum na região.

Entre outras tribos amazônicas, as palmeiras são mais utilizadas para decoração do corpo. Wallace (1853) relatou que diversas tribos amazônicas usam espinhos de Bactris gasipaes para fazer tatuagens; a fuligem produzida pela queima da resina era esfregada sobre os cortes, produzindo uma permanente coloração azulada. Em toda a Bacia Amazônica, espécies de Astrocaryum são amplamente usadas para decoração do corpo: os frutos pretos e brilhantes são transformados em pérolas, brincos e outros tipos de ornamentos (Levi-Strauss, 1950).

Finalmente, meu último dia entre os $\mathrm{Xi}$ riana-teri foi uma manhã de um dia de festa 
na tribo. Os índios estavam ocupados varrendo o chão da maloca com as duras inflorescências de Euterpe precatoria, as quais são ideais para esse fim. Aparentemente, esse é um costume bem difundido: já observei que inflorescências de outras espécies de Euterpe são usadas com o mesmo propósito pelos habitantes negros da floresta úmida do Choco, na costa Ocidental da Colômbia.

\section{CONCLUSÃo}

A importância material e espiritual das palmeiras na vida dos índios sul-americanos já foi documentada por diversos autores, incluindo Wallace (1853), Levi-Strauss (1950), Civrieux (1957), Braun (1968), Schultes (1974) e Wilbert (1976). Embora as palmeiras sejam muito importantes entre os Xiriana-teri, particularmente em sua dieta alimentar, eles as exploram em um grau muito menor do que muitas outras tribos da América do Sul. Em grande parte, isto se deve ao aspecto material da cultura deles, que é rudimentar em comparação com outras tribos amazônicas. Mas pode também ser devido a uma escassez de palmeiras na vizinhança de Toototobi.

Por exemplo, duas espécies que são particularmente valiosas entre as tribos da Amazônia - Mauritia flexuosa e Socratea exhorriza - não são comuns na vizinhança de Toototobi, e o missionário me informou que ambas espécies vêm se tornando escassas nos últimos anos. Parece que essas e outras espécies de palmeiras têm sido superexploradas durante o período relativamente longo (pelo menos 15 anos) que os Xiriana-teri residem em Toototobi. Como foi mencionado anteriormente, eles geralmente derrubam as palmeiras para coletar frutos ou palmito; segundo o missionário, este costume tem contribuído definitivamente para a falta de certas espécies de palmeiras na vizinhança de Toototobi. Cocco (1972) sugere que a escassez de palmeiras entre outras tribos de Yanomama é devida aos mesmos motivos. As pressões que uma tribo exerce sobre as palmeiras locais podem ser estimadas, quando se sabe que é necessário um mínimo dë aproximadamente 39.000 folhas de palmeiras para a cobertura dos tetos de uma aldeia típica de índios Waiká, na Venezue- la (Braun, 1968); além disso, essas folhas não são duráveịs e têm que ser trocadas cada três ou quatro anos.

Tais pressões sobre os recursos locais podem constituir um fator importante para explicar porque muitas tribos da Amazônia são ou têm sido tradicionalmente nômades fixando-se num determinado lugar por alguns anos e, então, mudando-se (Meggers, 1971). Entre os Xiriana-teri, entretanto, as vantagens de manter contato com o missionário (que fornece remédios, terçados, utensílios de cozinha, etc.) parecem ser maiores do que quaisquer desvantagens decorrentes da superexp!oração dos recursos locais. Além disso, é possivel que essas desvantagens não sejam realmente significativas entre esses índios. Pode-se verificar isso, por exemplo, através da relativa falta de utilização das fibras de palmeiras pslos Xiriana-teri. Entre a maioria das tribos ao norte da América do Sul, a principal fonte de fibras é a palmeira Mauritia flexuosa. Os índios Warao do baixo Orinoco utilizam as fibras desta espécie para a confecção de roupas, ornamentos, redes de dormir e de pescar, cestas, abanos, bandejas, e uma porção de outros objetos (Levi-Strauss, 1950; Wilbert, 1976). A ampla exploração de $M$. flexuosa feita pelos Warao é, sem dúvida, resultante da abundância dessa espécie no baixo Orinoco. Embora também ocorra na vizinhança de Toototcbi, ela é relativamente rara. Provavelmente, como conseqüência disso, os Xiriana-teri utilizam outras plantas para a obtenção de fibra vegetal. Além do cultivo do algodão, os índios obtêm suas fibras de uma espécie de Araceae, de Cecropia sp. (Moraceae), duma espécie de Cyclanthaceae, duma Annonaceae, de Couratari sp. (Lecythidaceae), etc. As fibras destas plantas são usadas no fabrico de roupas, cestas, sacos, cordas e diversos artigos que os índios de outros lugares confeccionam com fibras de palmeiras. A habilidade dos Xiriana. -teri em descobrir e explorar fontes alternativas da tecnologia revela uma flexibilidade que eles compartilham com os povos nativos de toda a parte tropical da América do Sul, segundo observação feita por Levi-Strauss (1950: 466-467):

$\mathrm{Na}$ parte tropical da América do Sul, os níveis gerais de cultura são determinados historicamente, 
ao invés de serem determinados pelos recursos vegetais locais, porque nenhum aspecto cultural fundamental parece depender diretamente do ambiente botânico... O fato notável é que, longe de depender do ambiente natural, os índios de toda a regiâo tropical da América do Sul apresentam uma habilidade excepcional para descobrir substitutos onde uma espécie vegetal está ausente.

\section{AGRADECIMENTOS}

O trabalho de campo que fundamentou o presente artigo foi realizado quando o autor estava apoiado por uma bolsa de estudos conseguida do Thomas J. Watson Foundation, em Providence, Rhode Island, EUA. A viagem a Toototobi foi arranjada pelo National Film Board do Canadá, em Montreal. O missionário, Sr. Bruce Hartman, forneceu informações realmente valiosas para o conteúdo deste artigo. Dois pesquisadores do INPA, Dr. Robert Pinger e Sr. Inocêncio de Souza Gorayeb, conseguiram informações adicionais durante viagens subseqüentes à tribo. Dr. Harold E. Moore Ir. ajudou na identificação das espécies de palmeiras no Bailey Hortorium. Finalmente, o manuscrito foi revisado pelo Dr. Ghillean T. Prance, do New York Botanical Garden, e pelos Drs. William A. Rodrigues e Nigel Smith, do Instituto Nacional de Pesquisas da Amazônia; a tradução para o português foi feita pela Profa. Elza Suely Anderson.

O autor gostaria de expressar seu reconhecimento a todas as pessoas e instituições mencionadas acima.

\section{SUMMARY}

This paper presents an examination of 20 of the major palm species utilized by a tribe of Yanomama Indians, the so-called Xiriana-teri, in the north of Amazonas state, Brazil. The Indian, Brazilian, and scientific names for each species are provided. The Xiriana-teri's uses of palms are examined in detail, and it is found that they utilize palms to a far lesser degree than do many other South American tribes. To a large extent this is due to the material aspect of their culture, which is rudimentary in comparison with other forest tribes. But the author maintains that, to some extent, palms are utilized to a lesser degree by the Xiriana-teri due to past over-exploitation of economically important species in the area adjacent to the village.

\section{Bibliografia CITADA}

BriUn, A.

1968 - Cultivated palms of Venezuela. Princi. pes, $12: 39-103 ; 111-136$.

Chagnon, N.A.

1968 - Yanomamö: The Fierce People. Holt, Rinehart \& Winston, N.Y.

CivrieuX, J.M.

1957 - Nombres folklóricos de algunas palmeras Amazonico-Guayanesas con apuntes etnobotánicos. Boletín de la Sociedad Venezolana de Ciencias Naturales 18: 195-233.

Cocco, P.L.

1972 - Iyëwei-teri: Quince Años entre los Yanomamos, Caracas, Venezuela.

Levi-Stauss, $\mathrm{C}$.

1950 - The use of wild plants in tropical South America. Handbook of South American Indians, $6: 465-486$. Cooper Square Publishers, N.Y.

MEGGERS, B.J.

1971 - Amazonia: Man and Culture in a Counterfeit Paradise. Aldine, Chicago.

Pechnik, E.; Mattoso, I.V.; Chaves, J.M. \& Borges, P.

1947 - Possibilidade de aplicação do buriti e tucumã na indústria alimentar. Arquivos Brasileiros de Nutrição, $4: 33-37$.

SChultes, R.E.

1974 - Palms and religion in the Northwest Amazon. Principes $18: 3-21$.

SChultes, R.E. \& Holmstedt, B.

1968 - De plantis toxicariis e mundo novo tropicale commentationes II. The ve getal ingredients of the myristicaceous snuffs of the Northwest Amazon. Rho. dora $70: 113-160$

SMOLE, W.J.

1976 - The Yanomama Indians: A Cultural Geography. Univ. of Texas Press. Austin.

Spiflman, R.S.; Migliazza, E.C. \& Neel, J.V,

1974 - Regional linguistic and genetic differences among Yanomama Indians, Scien. ce $184: 637-644$.

TAYLOR, K.I.

1974 - Sanumá Fauna: Prohibitions and Classifications. Monografia N.0 18, Fundación La Salle de Ciencias Naturales, Caracas.

WALlace, A.R.

1853 - Palm Trees of the Amazon. John Van Vorst, London.

WILBERT, J.

1976 - Manicaria saccifera and its cultural significance among the Warao Indians of Venezuela. Botanical Museum Leaflets, Harvard University 24 (10): 275-335; pl. LXVI - XCVIII. 